Vol. 14, No. 51, April, 2019, 553-558

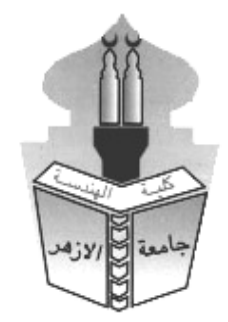

\title{
DERIVATION OF THE CIRCUIT PARAMETERS FOR A SLEEVE ROTOR INDUCTION MACHINE
}

\author{
Ahmed Menessy, M. Elwany and A. B. Kotb \\ Al-Azhar University,Faculty of Engneering,Electrical Department
}

\begin{abstract}
The field analysis using cylindrical coordinates for sleeve rotor induction machine is discussed. The magnetic field equations are carried out applying a simple model. The electric loading of rotor and the air gap flux density are calculated and plotted as a function of the machine speed. The effect of the sleeve material is taken into consideration.

The stator phase induced voltage is determined, and the air gap impedance is obtained in terms of machine design geometry. The individual sleeve rotor resistance, leakage reactance, and stator to rotor mutual reactance expressions are simplified for a minimum calculation effort.
\end{abstract}

\section{INTRODUCTION}

The sleeve rotor of a smooth conducting cylinder mounted on an iron core may allow a good starting machine conditions[1]. A simplified cross section of a sleeve rotor induction machine is shown in Fig.1. In addition to the conventional application, the sleeve rotor will lead to more development of future modified machine.

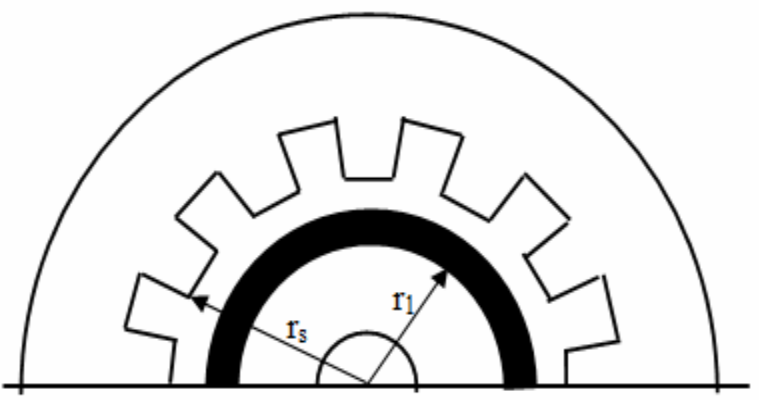

Figure.1, simplified cross section of sleeve rotor machine

Where $r_{s}$ is the inner stator radius, $r_{1}$ is the iron rotor radius. In order to completely describe the machine performance, it is necessary to derive an expression for the air gap impedance [2]. This can be carried out using the two-dimensional field theory in cylindrical coordinates $[3,4]$. It is possible to obtain the air gap impedance in a single step from the vector potential equation [5]. In addition, this method of analysis enables the effects of machine physical design data to be easily taken into account. 
Expressions for the individual equivalent circuit parameters of the sleeve rotor are derived and simplified by introducing some practical considerations [6,7]. These parameters are calculated and tabulated for different values of the sleeve rotor design data.

\section{THE FIELD ANALYSIS}

\subsection{Field Model}

The field problem is based on an idealized model of the sleeve rotor induction machine. The stator and rotor iron cores have very high permeability. Also, much effort can be saved by neglecting the current displacement in the rotor sleeve which is extremely weak. Accordingly, the field calculation is based on one-region model shown in Fig.2.

An infinitesimally thin sleeve sheet is assumed, to possess a finite surface conductivity:

$$
\sigma^{\prime}=\sigma \cdot t_{s}
$$

where $t_{s}$ and $\sigma$ are the actual values of the rotor sleeve thickness and its conductivity, respectively.

The stator windings are replaced by a current sheet carrying the stator electric loading As. The complex amplitude of the stator electric loading wave for $\mathrm{m}_{\mathrm{s}}$ phases is given by:

$$
\widehat{A} \mathbf{s}=-j m_{s} \frac{2 w_{s} k_{w}}{2 \pi} \sqrt{2} \text { Is }
$$

where $\mathrm{w}_{\mathrm{s}}$ is the number of stator turns per phase, and $\mathrm{K}_{\mathrm{w}}$ is the stator winding factor.

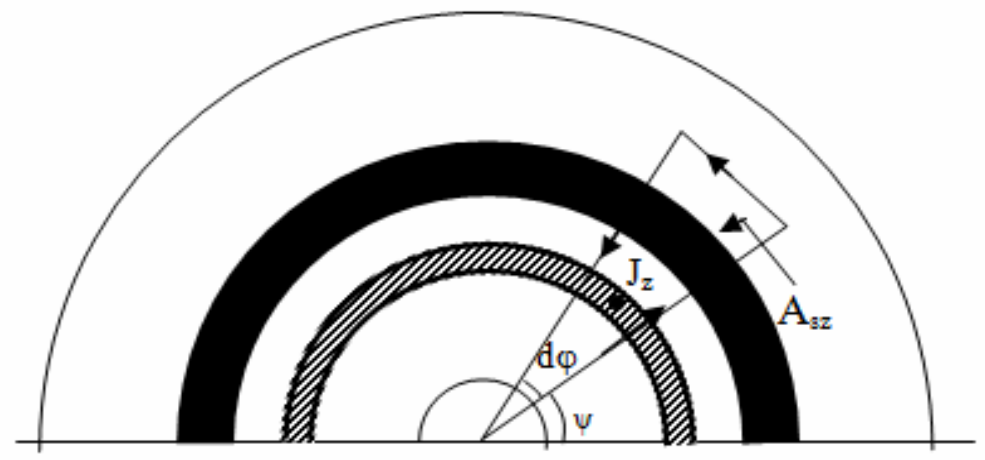

Fig. 2, one region model for a sleeve rotor

\subsection{The Solution of the Field Equation}

Only axial current is assumed to flow in the model so, the vector potential possess only an axial Z-component

$$
\mathrm{V}_{\mathrm{z}}(\mathrm{r}, \emptyset, \mathrm{t})=\operatorname{Re}\left(\mathrm{V}_{\mathrm{z}}(\mathrm{r}) \mathrm{e}^{\mathrm{j}(\omega t-\mathrm{P} \varphi)}\right) \text {, }
$$

where $\mathrm{P}$ is a number of pole pair.

From the magnetic and electric field equations, the differential equation for the complex amplitude of the vector potential $\mathrm{V}_{\mathrm{z}}$ is given in the form:

$$
\mathrm{r}^{2} \frac{\partial^{2} V_{z}}{\partial r^{2}}+\mathrm{r} \frac{\partial V_{z}}{\partial r}-\mathrm{P}^{2} \mathrm{~V}_{\mathrm{z}}=0 \text {. }
$$

The solution of this equation is:

$\mathrm{Vz}=\mathrm{C}_{1} \mathrm{rP}+\mathrm{C}_{2} \mathrm{r}-\mathrm{P}$,

the unknown integration constants $\mathrm{C}_{1}$ and $\mathrm{C}_{2}$ can be determine using the following model boundary conditions: 
At both air gap-stator and rotor boundaries, the tangential component of the magnetic field intensity is applied with taking the stator and rotor electric loadings into consideration.

$$
\begin{gathered}
-\frac{1}{\mu_{0}} \frac{\partial V_{z}}{\partial r} \mid \mathrm{r}_{\mathrm{s}}=\mathrm{A}_{\mathrm{s}}, \\
-\frac{1}{\mu_{0}} \frac{\partial V_{\mathrm{z}}}{\partial r} \mid \mathrm{r}_{\mathrm{1}}=\mathrm{A}_{\mathrm{r}} .
\end{gathered}
$$

The rotor electric loading $A_{r}$ can be, at first, expressed in terms of the magnetic vector potential as:

$\mathrm{A}_{\mathrm{r}}=-\mathrm{j} \sigma \omega \mathrm{sV}_{\mathrm{z}} \mid \mathrm{r}=\mathrm{r} 1$, from equation (5)

$\mathrm{A}_{\mathrm{t}}=-\mathrm{j} \sigma \omega \mathrm{s}\left[\mathrm{C}_{1} \mathrm{r}^{\mathrm{P}}+\mathrm{C}_{2} r^{-\mathrm{P}}\right]$

Solution of equations (6 and 7), gives the following results:

$$
\begin{aligned}
& \mathrm{C}_{1}=-\frac{\mu_{0} A_{s}}{P} r_{s}^{p+1} \frac{1+j K S}{r_{s}^{2 P}-r_{1}^{2 p}+j K S\left(r_{s}^{2 p} r_{1}+r_{1}^{2 p+1}\right)} \\
& \mathrm{C}_{2}=\mathrm{C}_{1} r_{s}^{2 P}+\frac{\mu_{0} A_{s}}{P} r_{s}^{2 p+1} \\
& \text { with } \mathrm{K}=\mathrm{w} \sigma \mu_{0} \mathrm{r} 1 / \mathrm{P}
\end{aligned}
$$

Substitution of $\mathrm{C}_{1}$ and $\mathrm{C}_{2}$ into Eq.(5), determines the vector potential Vz.

Thus, the radial flux density component at the stator surface is

$$
\mathrm{B}_{\mathrm{r}} \mid \mathrm{r}_{\mathrm{s}}=-\mathrm{j}\left[\mathrm{C}_{1} \mathrm{r}_{\mathrm{s}}^{\mathrm{p}-1}+\mathrm{C}_{2} \mathrm{r}_{\mathrm{s}}^{-(\mathrm{p}+1)}\right] \text {, }
$$

which can be used in determining the induced magnetization voltage. Equation (9a), can be represented in the form

$B r \mid r_{s}=B_{0} \frac{\left(r_{s}^{2 P}+r_{1}^{2 P}\right)+j K S\left(r_{s}^{2 P}-r_{1}^{2 P}\right)}{\left(r_{s}^{2 P}+r_{1}^{2 P}\right)+j K S\left(r_{s}^{2 P}+r_{1}^{2 P}\right)^{2} /\left(r_{s}^{2 P}-r_{1}^{2 P}\right)}$

where the no load flux density

$$
\mathbf{B}_{\mathrm{o}}=\mathbf{j} \frac{\boldsymbol{\mu}_{\mathrm{o}} \mathbf{A}_{\mathrm{s}}}{\mathbf{P}} \frac{\mathbf{r}_{S}^{2 \mathrm{P}}+\mathbf{r}_{1}^{2 \mathrm{P}}}{\mathbf{r}_{\mathrm{S}}^{\mathbf{P}}-\mathbf{r}_{1}^{2 \mathrm{P}}}
$$

The sleeve rotor electric loading is obtained from (7) and (8) to be

$$
A_{r}=A_{s} k \frac{r_{s}^{2 P}+r_{1}^{2 P}}{r_{s}^{2 P}-r_{1}^{2 P}} s \frac{r_{s}^{2 P}+r_{1}^{2 P}+j K S\left(r_{s}^{2 P}-r_{1}^{2 P}\right)}{r_{s}^{2 P}+r_{1}^{2 P}+j k s\left[\left(r_{s}^{2 P}+r_{1}^{2 P}\right)^{2} /\left(r_{s}^{2 P}-r_{1}^{2 P}\right)\right]}
$$

The air gap flux density and the rotor electric loading are important quantities for all the design procedure. The normalized flux density and rotor electric loading can be calculated and plotted as function of the machine speed. Fig.3, shows the variation of the amplitudes of radial flux density and the rotor electric loading as functions of the slip for high and low sleeve conductivities.

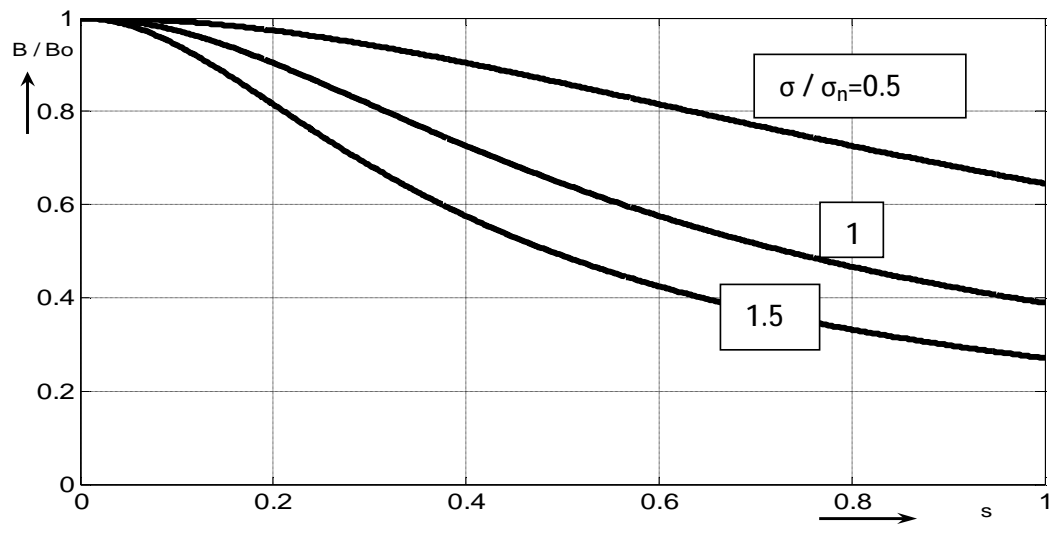

Fig. 3.a variation of $B$ as function of slip 


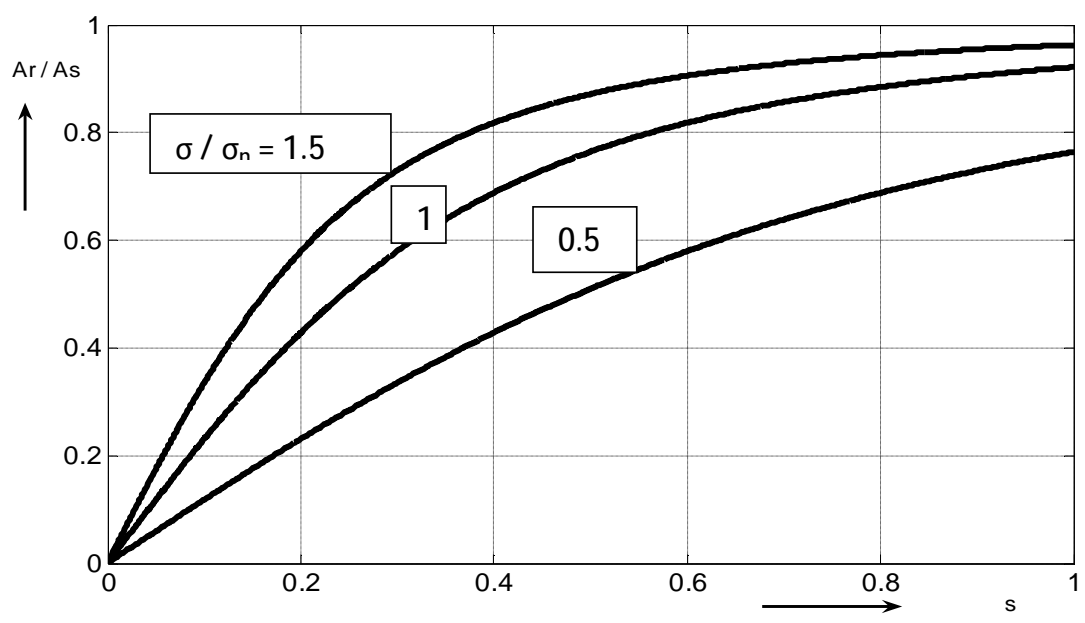

Fig. 3.b variation of Ar as function of slip

At synchronous speed, $\mathrm{s}=0.0$, no voltage is induced in the sleeve, and there is no rotor current and the magnetic field has its no load value Bo. Thus, the difference between the air gap flux density at load and the no load value is an immediate measure of the intensity of the rotor armature reaction.

The proceeding simple field analysis gives the air gap flux density and the rotor electric loading, now the next step is to determine an equivalent circuit representation for the sleeve rotor.

\section{THE AIR GAP IMPEDANCE AND THE SLEEVE PARAMETERS}

The main characteristics of the machine can be given if the stator electric loading is determined. In order to calculate the stator current, it is necessary to derive an expression for the air gap impedance $\mathrm{Z}_{\mathrm{g}}$.

The stator magnetization voltage induced by the air gap field is expressed by

$\mathrm{E}_{\mathrm{s}}=\mathrm{j} \frac{\omega}{\sqrt{2}}\left(\mathrm{w}_{\mathrm{s}} \mathrm{k}_{\mathrm{s}}\right) \mathrm{L} \frac{2 \pi r_{s}}{2 p} \cdot \frac{2}{\pi} \mathrm{B}_{\mathrm{g}} \mid \mathrm{r}_{\mathrm{s}}$

substituting from Eq. (8), the stator e.m.f. becomes

$\mathrm{E}_{\mathrm{s}}=\mathrm{j} \omega \mu_{0} \mathrm{~m}_{\mathrm{s}} \mathrm{L}\left(\mathrm{w}_{\mathrm{s}} \mathrm{k}_{s}\right)^{2} \frac{2}{\pi p^{2}} \frac{r_{s}^{2 P}+r_{1}^{2 P}+\left(j s \omega \sigma \mu_{0} r_{1 / p}\right)\left(r_{s}^{2 P}-r_{1}^{2 P}\right)}{r_{s}^{2 P}-r_{1}^{2 P}+\left(j s \omega \sigma \mu_{0} r_{1 / p}\right)\left(r_{s}^{2 P}+r_{1}^{2 P}\right)} \cdot I_{s}$

The air gap impedance is therefore given by

$Z_{\mathrm{g}}=\mathrm{E}_{\mathrm{s}} / \mathbf{I}_{\mathrm{s}}$

which may be written as

$\mathrm{Z}_{\mathrm{g}}=\mathrm{ja} \frac{r_{s}^{2 P}+r_{1}^{2 P}+j k s\left(r_{s}^{2 P}-r_{1}^{2 P}\right)}{r_{s}^{2 P}-r_{1}^{2 P}+j k s\left(r_{s}^{2 P}+r_{1}^{2 P}\right)}$

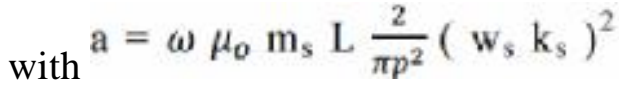

Extending both numerator and denominator of Eq. (13b) by $\mathrm{a} / \mathrm{K}\left(\mathrm{r}_{\mathrm{s}}^{2 \mathrm{P}}+\mathrm{r}_{1}^{2 \mathrm{P}}\right)^{2}$ and arranging the resulting equation, yield the following expression:

$$
\begin{aligned}
\mathrm{Z}_{\mathrm{g}}= & \mathrm{ja} \frac{\left(r_{s}^{2 P}+r_{1}^{2 P}\right)}{\left(r_{s}^{2 P}-r_{1}^{2 P}\right)}\left[\frac{a\left(r_{s}^{2 P}+r_{1}^{2 P}\right)^{2}}{4 k r_{s}^{2 P} r_{1}^{2 P}}+j s \frac{a\left(r_{s}^{4 P}-r_{1}^{4 P}\right)}{4 r_{s}^{2 P} r_{1}^{2 P}}\right] / \\
& \left\{\frac{a\left(r_{s}^{2 P}+r_{1}^{2 P}\right)^{2}}{4 k r_{s}^{2 P} r_{1}^{2 P}}+\mathrm{js}\left[\frac{a\left(r_{s}^{4 P}-r_{1}^{4 P}\right)}{4 r_{s}^{2 P} r_{1}^{2 P}}+\mathrm{a} \frac{\left(r_{s}^{2 P}+r_{1}^{2 P}\right)}{r_{s}^{2 P}-r_{1}^{2 P}}\right]\right\}
\end{aligned}
$$


The well-known equivalent circuit of Fig.4, is proposed to represent the induced voltage across the magnetizing reactance $X_{m}$ in parallel with the sleeve rotor impedance.

Referring to Fig.4, the impedance can be written in a form suitable for comparison with $\mathrm{Eq}(14)$ as:

$$
\mathrm{Z}_{\mathrm{g}}=\mathrm{jX} \mathrm{m} \frac{R_{r}^{\prime}+j s x_{1 r}^{\prime}}{R_{r}^{\prime}+j s\left(X_{m}+x_{1 r}^{\prime}\right)}
$$

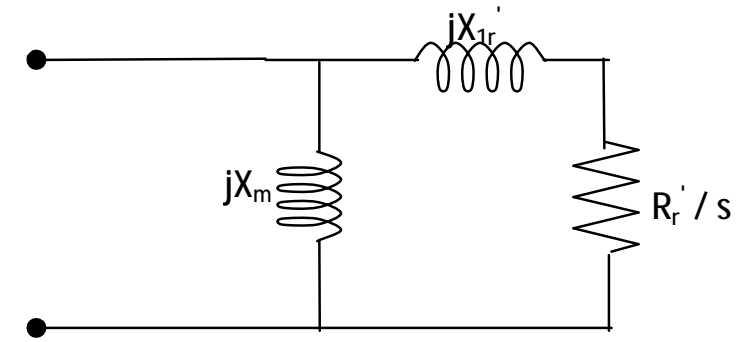

Fig. 4. usual sleeve rotor equivalent circuit

By comparing Eqs. (14) and (15), the individual parameters of the sleeve rotor equivalent circuit are obtained in the forms:

$$
\begin{aligned}
& X_{m}=a \frac{r_{s}^{2 P}+r_{1}^{2 P}}{r_{s}^{2 P}-r_{1}^{2 P}} \\
& x_{1 r}^{\prime}=a \frac{r_{s}^{4 P}-r_{1}^{4 P}}{4 r_{s}^{2 P} r_{1}^{2 P}}, \\
& R_{r}^{\prime}=a \frac{\left(r_{s}^{2 P}+r_{1}^{2 P}\right)^{2}}{4 k r_{s}^{2 P} r_{1}^{2 P}} .
\end{aligned}
$$

The equivalent circuit parameters are computed for different design data of a sleeve rotor.

Table 1, contains the design data for different machines and the corresponding values of Xm, $\mathbf{R}_{v}^{\prime}$, and $\mathrm{x}_{3 \mathrm{n}}^{\prime}$. The main design data are $: \mathrm{r}_{\mathrm{sn}}=5 \mathrm{~cm}, \mathrm{Ln}=10 \mathrm{~cm}, \mathrm{t}_{\mathrm{sn}}=0.5 \mathrm{~mm}, \mathrm{~g}_{\mathrm{n}}=0.2 \mathrm{~mm}$, and $\sigma_{n}=5107 \mathrm{~S}$.

Table 1, the design data and the corresponding equivalent circuit parameters.

\begin{tabular}{|c|c|c|c|c|c|c|c|}
\hline$\sigma / \sigma_{\mathrm{n}}$ & $\mathrm{t}_{\mathrm{s} / \mathrm{t}} \mathrm{sn}$ & $\mathrm{g} / \mathrm{g}_{\mathrm{n}}$ & $\mathrm{r}_{\mathrm{s}} / \mathrm{r}_{\mathrm{sn}}$ & $\mathrm{L} / \mathrm{L}_{\mathrm{n}}$ & $\mathrm{X}_{\mathrm{m}}$ & $\mathrm{R}_{\mathrm{n}}^{\prime}$ & $\mathrm{x}_{1 \mathrm{r}}^{\prime}$ \\
\hline 1 & 1 & 1 & 1 & 1 & 75 & 8.7 & .06 \\
$2 / 3$ & 1 & 1 & 1 & 1 & 75 & 13 & .06 \\
1 & $8 / 5$ & 1 & 1 & 1 & 52.4 & 5.5 & .086 \\
1 & 1 & 5 & 1 & 1 & 87.8 & 8.7 & .051 \\
1 & 1 & 1 & $4 / 5$ & 1 & 60 & 10.6 & .051 \\
1 & 1 & 1 & 1 & $4 / 5$ & 60 & 6.9 & .048 \\
\hline
\end{tabular}

Since the actual sleeve is replaced in the used model by an infinitesimally thin current sheet, there is no skin effect. Then, the individual equivalent circuit parameters are clearly independent on the rotor speed.

quince values. Consequently, the forward and backward current components, which enable the machine performance are determined. 


\section{CONCLUSIONS}

The results of the simplified analysis carried out here, give the principal expressions of the air gap flux density and the sleeve rotor electric loading. The sleeve resistance, leakage reactance, and the stator to rotor mutual reactance equations are simplified and carefully arranged for a minimum calculation effort. This method of analysis enables the effects of changing the design data to be directly taken into consideration.

\section{REFERENCES}

[1]. F.M. El-Lithy, "Operation of Two- Phase Sleeve - Rotor Induction Motor From 1- Phase Supply Using Phase Angle Control", AEIC, 93, Dec.18-21, PP,164-176, 1999.

[2]. M. EL-sayad, A.AL-koshairy : " Derivation of equivalent circuit of the L I M with endeffect taken into account," AEC., 1, vol. 9, pp. 73-93, 1989.

[3]. M. Shalaby: "Reactances of a permanent magnet synchronous machine equipped with a damper cylinder", AEIC. 4, vol. 5, pp. 352-365, Cairo 1995.

[4]. Md Ayubur Rahman Khan, Md Quamrul Ahsan "Development and Performance Analysis of a Two Phase Induction Motor in the Frame and Core of a Single-Phase Induction Motor" 8th International Conference on Electrical and Computer Engineering, Bangladesh, pp. 469-472. December, 2014

[5]. E, Mendrela, et al "Analysis of Electromagnetic Field in A Disk Induction Motor with Double-Sided Stator and Twin Rotors Using A 3-D Reluctance Network Method" PP286-289, Turkey,ICEM.99.

[6]. Yongguang Liu, Wenlei Liu and Nannan Cheng "Magnetic Field and Eddy Current Analysis of Permanent Magnet Eddy Current Coupling" IEEE Information and Automation Conference, PP. 2817-2822, China, 2015.

[7]. Wei Xu, Jianguo Zhu, Youguang Guo," Equivalent Circuits for Single-sided Linear Induction Motors" IEEE Transactions on Industry Applications, Vol. 46,pp.2410-2423, Nov/Dec 2010. 